\title{
The role of the pod in seed development: strategies for manipulating yield
}

Article

Accepted Version

Bennett, E. J., Roberts, J. A. and Wagstaff, C. (2011) The role of the pod in seed development: strategies for manipulating yield. New Phytologist, 190 (4). pp. 838-853. ISSN 0028-646X doi: https://doi.org/10.1111/j.1469-8137.2011.03714.x Available at https://centaur.reading.ac.uk/26411/

It is advisable to refer to the publisher's version if you intend to cite from the work. See Guidance on citing.

To link to this article DOI: http://dx.doi.org/10.1111/j.1469-8137.2011.03714.x

Publisher: Wiley-Blackwell

All outputs in CentAUR are protected by Intellectual Property Rights law, including copyright law. Copyright and IPR is retained by the creators or other copyright holders. Terms and conditions for use of this material are defined in the End User Agreement.

\section{www.reading.ac.uk/centaur}

\section{CentAUR}

Central Archive at the University of Reading

Reading's research outputs online 


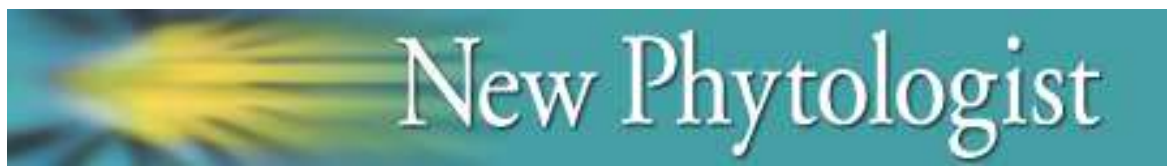

The Role of the Pod in Seed Development: Strategies for Manipulating Yield

\begin{tabular}{|r|l|}
\hline Journal: & New Phytologist \\
\hline Manuscript ID: & NPH-TR-2011-11339.R1 \\
\hline Manuscript Type: & TR - Commissioned Material - Tansley Review \\
\hline Date Submitted by the & n/a \\
\hline Complete List of Authors: & $\begin{array}{l}\text { Bennett, Emma; University of Reading, Department of Food and } \\
\text { Nutritional Sciences } \\
\text { Roberts, Jeremy; Nottingham University, School of Biosciences } \\
\text { Wagstaff, Carol; University of Reading, Department of Food and } \\
\text { Nutritional Sciences, Centre for Food Security, }\end{array}$ \\
\hline Key Words: & $\begin{array}{l}\text { pod, seed, silique, senescence, resource allocation, yield, } \\
\text { Arabidopsis, Brassica }\end{array}$ \\
\hline
\end{tabular}


1 Tansley Review

\section{The Role of the Pod in Seed Development: Strategies for Manipulating Yield}

3 Emma J Bennett ${ }^{1}$, Jeremy A Roberts ${ }^{2}$, and Carol Wagstaff ${ }^{1}$

$4 \quad{ }^{1}$ Department of Food and Nutritional Sciences, University of Reading, PO Box 226, Whiteknights, Reading,

5 RG6 6AP, UK; ${ }^{2}$ Plant and Crop Sciences Division, School of Biosciences,University of Nottingham,Sutton

6 Bonington Campus, Loughborough, Leicestershire, LE12 5RD, UK

7

8 Author for correspondence:

9 Carol Wagstaff

$10 \quad$ Tel: +441183785362

11 Email: c.wagstaff@ reading.ac.uk

14 Key words: pod, seed, silique, senescence, resource allocation, yield, nutrition, Brassica, 15 Arabidopsis 
The Role of the Pod in Seed Development: Strategies for Manipulating Yield

\section{Summary}

Pods play a key role in encapsulating the developing seeds and protecting them from pests and pathogens. In addition to this protective function it has been shown that the photosynthetically active pod wall contributes assimilates and nutrients to fuel seed growth. Recent work has revealed that signals originating from the pod may also act to co-ordinate grain filling and regulate the reallocation of reserves from damaged seeds to those that have retained viability. In this review we consider the evidence that pods can regulate seed growth and maturation, particularly in members of the Brassicaceae family, and explore how the timing and duration of pod development might be manipulated to enhance either the quantity of crop yield or its nutritional properties.

\section{Introduction}

A pod, or silique as it is known in the Brassicaceae, is a photosynthetically active organ that encloses the seeds during their development. Once seed maturation is complete the bivalve pod splits longitudinally and its contents are released. In this review we will focus our discussions primarily on members of the Brassicaceae family and seek to demonstrate that the function of the pod extends far beyond simply safeguarding the maturing seeds. In this review we will refer to siliques by the more generic term pod, as much of the data generated from the study of Brasicaceous species has wider relevance across other families in the plant kingdom that reproduce through the formation of pods which enclose their seeds. Whilst pods are not essential for an individual's existence they play a paramount role in the survival of a species and could therefore be considered as one of the most important organs of a plant. In light of this it is perhaps surprising that relatively little research has been carried 
out on pod growth and development and how this might be manipulated to enhance crop yield.

Seeds constitute an important source of dietary protein due to their high concentrations of seed storage proteins (SSPs) which can help alleviate malnutrition under circumstances when the consumption of animal protein is low. In the Brassicaceae family the main SSPs can be classified into either $12 \mathrm{~S}$ globulins or $2 \mathrm{~S}$ albumins, precursors of which are synthesised on the rough endoplasmic reticulum and, after maturation, reside in protein storage vacuoles within the seed (Herman \& Larkins, 1999). Despite their nutritional benefits, seeds are deficient in some essential amino acids (see Mandal \& Mandal, 2000 for a review) and are therefore incapable of completely alleviating protein malnutrition without supplementation. Hence yield enhancement is not only concerned with net increases in marketable produce but also in strategies to improve nutritional quality. The latter term encompasses many different aspects of seed composition but with regard to protein it represents the correlation between the amino acid profile of a seed and a balanced diet as recommended by the World Health Organisation (WHO) (Mandal \& Mandal, 2000). Recent figures from WHO estimate that whilst the number of underweight children has fallen to $16 \%$ of the global population a simultaneous increase in inhabitants means that this still represents 104 million undernourished children worldwide (World Health Organisation, 2010). In stark contrast, a global obesity epidemic is also occurring and as of the year 2000 WHO estimated that 300 million adults worldwide were obese (World Health Organization, 2000), a larger group than those considered to be undernourished. Intriguingly, there is evidence that one approach to help alleviate obesity might be to improve SSP levels and seed nutritional quality as high protein diets have been shown to assist in reducing and maintaining a healthy body mass (Claessens et al., 2009). 

highlighted by Ban Ki-moon, speaking at a UN summit on solving the world's food crisis in

2008, when he predicted that there would need to be a $50 \%$ increase in global food production by 2030. Thus, a rising world population (predicted to reach around 9 billion by 2050), against a backdrop of climate change, makes the need to optimise yield of paramount importance. Maximising the efficiency of crop growth is one way global food demands can be met, and with a growing body of evidence that the pod directly influences seed composition it is bringing our ability to manipulate pod growth and development to the forefront of yield enhancement strategies.

\section{Pod Structure and Development}

The Brassicaceae family contains more than 3000 species and these produce nonfleshy fruit in the form of a silique that emerges from the gynoecium following ovule fertilisation. Recent transcript profiling analyses has provided evidence to support the assertion that the pod wall represents a modified leaf (Ma et al., 2005; Scutt et al., 2006; Wagstaff et al., 2009). In the model Brassica species Arabidopsis the pod wall (pericarp) is composed of two fused carpels that undergo cell expansion between fertilisation and maturity, causing the pod to elongate about seven times its initial length between fertilisation and maturity (Sessions \& Zambryski, 1995; Louvet et al., 2006) . In contrast, the pods from members of the Fabaceae family are formed from a single carpel so, whilst the fruit from both families is commonly referred to as a pod, the term silique is reserved for members of the Brassicaceae family.

\subsection{The Pod Wall Structure}

The pericarp has been classified into three functional cell layers; the exocarp, mesocarp and endocarp, which are all characteristic components of fruit cell walls. The 
exocarp comprises a single celled epidermal layer that is populated with stomata to facilitate gaseous exchange. The mesocarp is composed of layers of chlorenchyma cells that are rich in chloroplasts (Sessions \& Zambryski, 1995). Finally, the endocarp consists of two dissimilar cell layers, a surface layer (ena) made up of large thin walled cells and an inner layer (enb) formed from small tightly packed cells as a result of several anticlinal cell divisions (Spence et al., 1996). The silique wall is not entirely uniform and a narrow dehiscence zone (DZ), approximately two cell layers in width, spans the length of the silique between the valve and the replum (for review see Ferrandiz et al., 1999; Ferrandiz, 2002). Such pericarp differentiation is necessary to target cellular degradation to the middle lamella between DZ cells, thus allowing the pod to shatter and release its mature seeds (Meakin \& Roberts, 1990). Ultrastructural analysis of mature green silique walls has revealed developmental patterns associated with the onset of senescence, as they contain fewer thylakoids per granum than would normally be observed in leaf plastids (Wagstaff et al., 2009). This feature, often associated with the structural reorganisation of thylakoid membranes, accompanies reduced PSI and PSII activity during senescence (Prakash et al., 2001). Additionally, the decrease in chlorophyll in the pod wall precedes the decline observed in seeds which remain photosynthetic for longer (Wagstaff et al., 2009); together these ultrastructural and physiological features may be required for optimisation of photosynthate accumulation in seeds. The consequences of such structural changes may be to enable a greater percentage of incident light to reach the seeds. In a crop such as oilseed rape (Brassica napus) this could potentially enhance its yield as ATP and NADPH are predicted to be required for the biosynthesis of seed storage products such as lipids (Fuhrmann et al., 1994; Aach \& Heise, 1998; Schwender et al., 2004; Goffman et al., 2005). Given that only 20-30\% of the incident light passes through the silique wall, and the spectral quality also changes in favour of the far red (FR) wavelengths, oilseed rape seeds develop within a shaded environment. These FR 
wavelengths may also trigger the induction of seed dormancy, which is a common feature of freshly harvested seed from this crop, since such wavelengths are known to inhibit seed germination (Borthwick et al., 1951). Using similar strategies to shade leaves, seeds have a lower chlorophyll $\mathrm{a} / \mathrm{b}$ ratio to enable them to capture a greater amount of the available light (Eastmond et al., 1996; King et al., 1998) and it is reasonable to assume that selection pressures would have favoured a temporal separation of the loss of photosynthetic capacity between pods and seeds. One advantage of having a temporal division in photosynthetic maximums is that a greater amount of incident light is capable of reaching the developing seeds which can enhance ATP production leading to increased oil synthesis (Ruuska et al., 2002). High levels of anthocyanins are contained within the testa of M. truncatula seeds, which not only give the seeds colour (Abirached-Darmency et al., 2005) but potentially impart protection against photo-oxidative stress; for a review of anthocycanin function see Archetti et al. (2009). As the silique wall begins the process of senescence and chlorophyll catabolism the enclosed seeds, which have matured within a shaded environment, are slowly exposed to higher levels of incident light. Consequentially the anthocyanins in the seed testa may afford some protection against increased UVB exposure and associated build up of reactive oxygen species.

\subsection{Pod Wall Development}

Despite being characteristically viewed merely as a protective organ, for instance the pod morphology of alfalfa has been shown to be instrumental in safeguarding seeds against chaliced wasps (Small \& Brookes, 1984), the role of the pod appears to alter during the course of development. For instance, transcriptional profiling of the pod wall at different developmental stages has revealed that the observed changes in pod anatomy and chlorophyll levels throughout pod maturation correlated with alterations in transcription factor expression patterns (Wagstaff et al., 2009). Indeed there is a strong association between pod 
development and seed size (Pechan \& Morgan, 1985) which has prompted the suggestion that pod length could be used as an indication of crop yield (Diepenbrock, 2000).

\section{The Pod as a Sink in Plant Resource Allocation}

The allocation of resources to developing siliques remains poorly understood, with the majority of research concentrating on nutrient remobilisation out of senescing leaves.

Nevertheless, it has been established that at anthesis the pod becomes a resource sink capable of storing remobilised nitrogen $(\mathrm{N})$ and carbon $(\mathrm{C})$ for utilisation upon germination (Harvey, 1973; BuchananWollaston, 1997; Diepenbrock, 2000; Rossato et al., 2001; Schiltz et al., 2005). This recycling of nutrients is essential for producing seeds that contain high concentrations of storage compounds such as proteins, lipids and starch, which is why the phloem remains functional throughout senescence (Feller \& Fischer, 1994). Unlike other plant organs, such as taproots, the pod is considered a sink throughout development (Rossato et al., 2001) although in practice the pod wall contributes assimilates to the developing embryo during the final stages of seed maturation (Rochat \& Boutin, 1991), for example, $20 \%$ of the $\mathrm{N}$ accumulated in pea seeds has been shown to be remobilised from the adjacent pod wall (Schiltz et al., 2005).

\subsection{Nitrogen Uptake}

There is a considerable body of evidence to support the view that resources from vegetative parts of the plant are remobilised into the pod (Harvey, 1973; Flinn et al., 1977; Schiltz et al., 2005). ${ }^{15} \mathrm{~N}$ labelling experiments have demonstrated that about $48 \%$ of the $\mathrm{N}$ cycling through oilseed rape ends up in mature pods (Rossato et al., 2001) and it is presumed that most of this originates from vegetative tissues, since little $\mathrm{N}$ uptake occurs during flowering and pod development. This observation indicates that $\mathrm{N}$ fertilisation after flowering would only have minimal effects on plant yield. Our understanding of the pathways involved 
in remobilising $\mathrm{N}$ from the leaves to developing pods are superficial, however, recent insights into the metabolic role of the enzyme pyruvate orthophosphate dikinase (PPDK) in metabolism may have shed some light on this problem. PPDK interconverts pyruvate and phosphoenolpyruvate and is central to photosynthesis in C4 plants, but it is also up-regulated during leaf senescence of $\mathrm{C} 3$ plants where it functions in a pathway that generates the transport amino acid glutamine, which is then loaded into the phloem. Over-expressing cytosolic PPDK results in more efficient amino acid transport and hence $\mathrm{N}$ remobilisation from the leaves is accelerated during senescence, leading to increases in Arabidopsis seed weight and $\mathrm{N}$ content, but not seed number (Taylor et al., 2010). One possible explanation for these observations is that an extended growth period and larger rosette size might provide a greater initial resource pool in the vegetative tissues from which to reallocate storage compounds. However, while elevating the soil $\mathrm{N}$ content has been shown to enhance crop yield by increasing the number of pods per plant such an approach does not impact upon pod or seed weight (Allen \& Morgan, 1972). This implies that the reproductive strategy of oilseed rape is to direct assimilates into additional pods when resources are plentiful rather than to produce seeds containing a greater concentration of storage products (Gammelvind et al., 1996). Combining the increased $\mathrm{N}$ remobilisation efficiency of PPDK over-expressers with higher soil $\mathrm{N}$ might substantially enhance yield in terms of both pod quantity and quality.

\subsection{Leaf Senescence}

Leaf senescence is a highly co-ordinated process that enables maximum recovery and remobilisation of nutrients from the leaves. At the onset of Arabidopsis leaf senescence there is an increase in the transcription of genes such as the ABC, sugar, peptide, amino acid and cation transporters in addition to the potential mobilisation of sulphur released upon protein degradation (Buchanan-Wollaston \& Ainsworth, 1997). The start of leaf senescence is also accompanied by a concomitant increase in pod $\mathrm{CO}_{2}$ metabolism indicating that this organ has 
an elevated rate of photosynthesis (Gammelvind et al., 1996; Robinson \& Hill, 1999), potentially to enable nutrient uptake into the pod. As pods are photosynthetic organs, capable of generating reducing energy and ATP, their exact sink requirements are still a matter of debate. In oilseed rape, Allen and Morgan (1972) predicted that pods were capable of supporting their own growth, but subsequent examination of different Brassica species indicates that the photoassimilate contribution by the pod wall to developing seeds might be species specific (Ramana \& Ghildiyal, 1997). The mechanisms by which resources are allocated into individual seeds is unknown for, whilst Arabidopsis fills its seeds in a uniform, co-ordinated manner, other species such as peas have larger and heavier seeds in the middle of their pods compared to those at the distal and proximal extremes of the pod (Harvey, 1973). A fuller understanding of the source-sink relationship could prove to be crucial in improving crop yield as the sinks compete for the available resources.

\subsection{Leaf-Pod Push-Pull Export and Import System}

In some species the import of resources into the developing seeds is closely correlated with the capacity of leaves to export assimilates (Wittenbach \& Vernon, 1983). However, in Arabidopsis the development of reproductive structures only minimally influences leaf senescence with organ age having a far greater effect. Selective pod removal had almost no impact on individual leaf senescence in Arabidopsis, but overall plant longevity was increased by $20-50$ days according to Nooden \& Penney (2001), but in our hands the rosette leaves remained green if all but the main inflorescence was removed (Figure 1). Whole plant senescence can be delayed through the removal of seeds from both pea and soybean pods (Lockhart \& Gottschall, 1961; Lindoo \& Nooden, 1977) and it has been proposed that the pea seed coat determines sink strength (Rochat \& Boutin, 1992). Further work implies that this 'pulling power' is coordinated with the breakdown of leaf storage products (Taylor et al., 2010) and it is likely that the pod sink strength is not a fixed entity but instead co-ordinated 
throughout development to balance the 'needs' of the seeds, for instance $\mathrm{N}$ remobilisation decreases during the later stages of seed filling (Schiltz et al., 2005). The plastic nature of whole plant resource allocation can be observed in many of the soybean de-podding experiments performed by Nooden and co-workers (Lindoo \& Nooden, 1976; Lindoo \& Nooden, 1977; Nooden et al., 1978; Nooden \& Murray, 1982) and from studies examining sterile mutants (Nooden \& Penney, 2001). The number of pods also has the capacity to affect leaf photosynthesis, for instance selective pod removal in soybeans leads to reduced rates of $\mathrm{CO}_{2}$ exchange within these plants, probably due to stomatal closure, a consequence of increased photoassimilate accumulation within the leaves brought about by having fewer sinks to export resources to (Setter \& Brun, 1980; Wittenbach \& Vernon, 1983). This indicates the presence of a dynamic feedback loop in which the pods signal their resource requirements to the leaves, causing the remobilisation of photoassimilates relative to the signal strength received (Figure 1). Hence, when fewer pods are present in de-podded plants the leaves temporarily halt photoassimilate production in response to an accumulation of carbohydrate in the leaves and an absence of 'pull' from the pods. An alternative view is that the sinks do not pull in resources but instead 'free load' by altering the conductance of plasmodesmata at the phloem-sink interface to affect the rate of nutrient unloading, matching this to their resource requirements (see Lalonde et al., 2003 for a review).

Maximum remobilisation capacity is critical for $\mathrm{R}$ selected species, such as Arabidopsis, whose reproductive strategy is to produce viable seeds as quickly as possible. A potential response to such a life history trait is that Arabidopsis determines its seed set based upon the nutritional supply during the reproductive stage, rather than it being predetermined by growth and development during the vegetative phase, a trait associated with weeds growing in unpredictable environments (Schulze et al., 1990). Such a trait could be desirable for commercial Brassica and legume crops to improve seed set. 


\section{Resource Transport into the Seeds via the Pod}

\subsection{Transport from the pod wall}

The ability to manipulate resource partitioning and assimilate transport into the seeds and pods could help maximise overall yield (Wardlaw, 1990). Studies using detached pods have shown that the photosynthetic tissues of the pod wall are capable of generating $60 \%$ of seed assimilates (reviewed in Diepenbrock, 2000), although it must be noted that in vitro pod growth results in a decrease in internal pod $\mathrm{O}_{2}$ concentrations compared to growth in vivo, which can alter the amount of storage compound within a seed (Musgrave et al., 2008). As development progresses there is an increase in the compounds exported from the pod wall into the seeds. During this period the pod wall efficiently remobilises any accumulated $\mathrm{N}$ into the seeds such that upon harvest $80 \%$ of the total shoot $\mathrm{N}$ in oilseed rape has been relocated into the seeds. Seeds are capable of receiving the majority of their amino acids through the phloem-mediated pathway(Okumoto et al., 2002), which can come from the pod wall as well as vegetative organs. Such remobilisation decreases during the later stages of development (Schjoerring et al., 1995; Schiltz et al., 2005), potentially due to the absence of sucrose synthase (SUS) activity in the pod wall and funiculus (Fallahi et al., 2008) which is predicted to provide energy for phloem loading and unloading of solutes at this site (Fallahi et al., 2008). Whether photoassimilates generated during pod wall photosynthesis can be reallocated to other pods is not yet clear, but such a mechanism could prove valuable given that pods higher up in the canopy receive a greater amount of incident light and are thus capable of increased photosynthetic rates whilst being largely exempt from the problems of self shading. 
The import of resources into the pod is primarily concerned with phloem unloading,

267

268

269

but this area has received little attention compared with phloem loading at the source site (Patrick, 1997), which is partly due to the great diversity between different sink types. Seeds are well adapted for the uptake of photoassimilates translocated from the pod wall. In Medicago truncatula the micropylar region of the seed coat, a small opening in the outer epidermis of the ovule located at one end of the seed, contains a vascular system believed to be instrumental in nutrient transport into the developing seed (Abirached-Darmency et al., 2005). Photoassimilates enter the funiculus which leads to the vascular bundle in the seed coat where unloading can occur (Van Dongen, 2003; Stadler et al., 2005).

Whilst there is a comprehensive understanding of how resources are transported via the xylem and phloem to the pod junction subsequent steps describing the mechanism of transfer from the pod petiole to the seed-funiculus are still poorly defined. The current notion is that transport initially occurs through the symplastic pathway using plasmodesmata and is driven by simple diffusion and or bulk flow. However solutes must be subsequently translocated via apoplastic pathways to move between seed and pod tissues, plus the presence of a selectively permeable apoplastic pathway connecting the maternal tissue and phloem helps prevent nutrient loss. In addition, an apoplastic pathway can run in parallel to the symplastic pathway between the phloem and maternal tissues, but the exact details surrounding resource transport into the seeds are still under review (Patrick \& Offler, 2001; Lalonde et al., 2003).

It is predicted that the concentration of storage products within the seeds helps regulate the efficiency with which resources are transported around the plant (Schulze et al., 1994). One such mechanism of regulating supply and demand between the phloem and pod involves the reduction of apoplastic sucrose levels within sink tissues (reviewed in Patrick, 1997), a further indication that the pods act as sinks to pull resources in from the surrounding 
290

291

292

293

294

295

296

297

298

299

300

301

302

303

304

305

306

307

308

309

310

311

312

313

tissues. This flow of solutes is driven along the phloem by passive transport caused by differences in turgor pressure between the source and sink organs (Patrick, 1997).

\subsection{Nutrient transporters}

Numerous nutrient transporters are located within the funiculus and at the base of the pod in the pedicel. One of the many Arabidopsis sulphate transporters, SULTR2-1, controls the translocation of sulphur into seeds and is potentially capable of regulating the import of this element into seed storage proteins, (Awazuhara et al., 2005). Regulating sulphate uptake into pods can directly impact upon both seed quality and yield yet SULTR2-1 mRNA levels do not alter regardless of the sulphur concentration that plants are grown in, highlighting the fundamental importance of this transporter in maintaining an import system (Awazuhara et al., 2005).

Since only small amounts of nitrate are directly translocated from the roots into the seeds (Chopin et al., 2007), by itself nitrate is unlikely to contribute much $\mathrm{N}$ towards seed nutrition but instead it is predicted to serve as a signalling molecule, or to alter the osmotic balance during the early stages of seed filling (McIntyre, 1997; Chopin et al., 2007), although during periods of nitrogen deficiency it was postulated that nitrates might have a greater role to play in enhancing seed nutrition (Fan et al., 2009). As the Arabidopsis amino acid transporter AAP8, which has a similar expression pattern to SULTR2-1 (Awazuhara et al., 2005), is present in the funiculus and pod vascular tissue it is predicted to be responsible for enabling the import of organic nitrogen into the seeds (Okumoto et al., 2002), leading to the hypothesis that amino acids enter the pod vascular tissue and are transported though the funiculus where they are imported into seeds at the micropylar region (Awazuhara et al., 2005).

\subsection{Impact of seed wounding}


Although seeds clearly function as a sink for assimilates and nutrients during development the impact of seed wounding or abortion on transport processes has received little attention. All seeds within a pod are connected to the vascular trace by the funiculus. In Arabidopsis, the response regulator gene $A R R 22$ has been shown to be expressed specifically at the junction between the funiculus and chalazal tissues (Gattolin et al., 2006; Horak et al., 2008). Despite chalazal tissues important role in supplying nutrients to the developing seeds, silencing of $A R R 22$ does not give rise to a morphologically detectable phenotype (Gattolin et al., 2006; Horak et al., 2008), although ectopically expressing the gene results in the

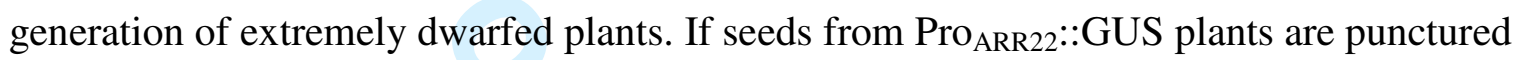
then expression of the reporter is rapidly up-regulated in the chlazal region indicating that the ARR22 transcript accumulates as a result of injury to the seed (Gattolin et al., 2006). Recent research has revealed that the wounding of Arabidopsis pods is accompanied by rapid changes in transcript profile, causing mRNAs encoding seed storage proteins to dramatically decline, whereas those encoding proteins involved in proteolysis substantially increase, precise mechanism that co-ordinates seed filling within an individual pod is unknown and, whilst in a weed such as Arabidopsis this is uniform, the trait may have been lost in some 
spatial and temporal expression of $A R R 22$ make it a strong candidate for having a role in the co-ordination process and by manipulating its expression it might be possible to extend or reduce the seed filling period.

\section{Pod Senescence and Dehiscence}

\subsection{Method of Seed Dispersal}

At a plant level, uncoordinated pod senescence and dehiscence is advantageous and limits the seed loss that can occur if ripe pods shatter during temporarily adverse environmental conditions that subsequently inhibit germination of the next generation of plants. However, in a commercial setting, premature and uncoordinated pod shattering results in substantial pre-harvest losses and therefore significantly reduces net yield. For instance up to $20 \%$ of oilseed is lost per annum due to premature pod shatter whilst in Birdsfoot trefoil (Lotus corniculatus L.) this can be as high as $50 \%$ during adverse weather conditions (MacLeod, 1981). Such events can also impede subsequent crop growth due to the emergence of volunteer plants in the following growing season. Hence preventing premature pod shatter would instantly increase net crop yield, which, aside from the economic implications, would undoubtedly contribute to a viable solution of sustaining an escalating world population. Due to its economic importance, Brassica napus is a popular candidate species for investigating methods aimed at preventing or delaying pod shatter. Nevertheless, the development of a genotype that fails to shatter may not provide an ideal solution to this problem as this could compromise the postharvest processing chain due to difficulties in removing seeds from the pods without damage. A more amenable approach might be to delay or suspend the final stages of pod development after seed maturation to prevent individual pods shattering until all the pods have fully developed, at which time an internal or external stimulus could be applied to co-ordinate pod shattering across the crop. 


\subsubsection{Dehiscence}

The pod wall of Brassicaceae family members is typically composed of two valves connected by a replum. In between these lignified cell types is a narrow band of valve margin cells that forms the dehiscence zone (DZ) and remains a non-lignified separation layer (SL) throughout pod development (Ferrandiz, 2002). Pod shattering is either initiated at the base of the pod where the pedicel meets the replum, as in oilseed rape (Morgan et al., 2000), or at the pod tip and will continue along the DZ until the valves have completely separated (Davies \& Bruce, 1997). A highly co-ordinated sequence of cellular and molecular events are required to bring about the dissolution of the middle lamella between cells of the DZ, and separation is precipitated in part by water loss from the pod wall, causing the valve cells to shrink and creating the tension necessary to pull them apart (Meakin \& Roberts, 1990; Liljegren et al., 2004).

\subsubsection{Genetic dissection of dehiscence}

Much of the research undertaken in this area has focused on the differentiation and development of the DZ in the model species Arabidopsis. Formation of this non-lignified region is controlled by several MADS-Box genes which are capable of not only negatively regulating each other's expression but also acting independently in the valve, valve margin and replum cell layers. Expression of the functionally redundant SHATTERPROOF 1 (SHP1) and SHATTERPROOF 2 (SHP2) genes specifies the DZ and promotes lignification of adjacent cells (Flanagan et al., 1996; Liljegren et al., 2000). To confine the DZ to the valve margin FRUITFULL (FUL) represses INDEHISCENT (IND), ALCATRAZ (ALC) SHP1 and SHP2 expression in the adjacent valve cells as well as preventing lignification of the DZ $(\mathrm{Gu}$ et al., 1998; Ferrándiz, 2000; Rajani \& Sundaresan, 2001; Liljegren et al., 2004). The transcription factor SPATULA (SPT) might also function in pod dehiscence since its expression is identical to that of $F U L$ from mid pod development leading the authors to 
propose that these two genes share regulatory roles (Heisler et al., 2001), although more recent work from the same group has suggested that SPT is regulated by IND (Groszmann et al., 2010). SHP1 and SHP2 transcriptionally activate $A L C$ expression, which is required for establishing the SL between the valve margin and repulm (Rajani \& Sundaresan, 2001). At the onset of the pod shatter process, pectin in the SL cell walls is degraded by hydrolytic enzymes, such as ADPG1 and ADPG2 polygalacturonase (PG) enzymes which, in combination with increased pod wall tension, enables dehiscence to proceed (Ogawa et al., 2009). In addition to the PG enzymes it is predicted that a cyclic nucleotide-gated ion channel, AtCNGC2, might be involved in regulating programmed cell death within the DZ cells in Arabidopsis (Köhler et al., 2001).The IND gene also functions downstream of the SHP transcription factors and is similarly required for differentiation of the valve margin cells, as well as lignification of the adjacent valve and replum cell layers (Liljegren et al., and SHP2, since low expression levels can be detected in the valves in the $s h p / s h p 2 / f u l$ triple mutant (Ferrándiz, 2000; Liljegren et al., 2004). IND forms a self regulating network and is also required for the expression of ADPGl in the DZ (Ogawa et al., 2009); thus if IND is not expressed to define the valve margins then the PG enzyme which would breakdown this cell layer also fails to be produced. All five transcription factors involved in patterning the silique: IND, ALC, SHP1, SHP2, and FUL are required for lignification of the valve layer and hence seed dispersal (Liljegren et al., 2004). Furthermore, these MADS-box genes are predicted to be repressed by REPLUMLESS (RPL) which functions to specify the replum cell layer adjacent to the valve margin and hence maintain the $\mathrm{DZ}$ at the valve margin (Roeder $e t$ al., 2003). create an indehiscence phenotype, for instance in the FUL gain of function (Ferrándiz, 2000), 
shp1shp2 double knockout (Liljegren et al., 2000), IND loss of function (Liljegren et al., 2004) and $A L C$ loss of function (Rajani \& Sundaresan, 2001) plants the DZ is prevented from forming properly, demonstrating that the genetic manipulation of orthologues in Brassica species might be a suitable strategy for controlling pod shatter. However, there are potential limitations to this strategy as ectopic expression of the $F U L$ gene in $B$. juncea has been revealed to make pods resistant to threshing (Østergaard et al., 2006). A more recent approach showed that it is possible to fine-tune the severity of the shatter phenotype through inducing point mutations in Brassica orthologues of the IND gene and selecting those variants with a commercially useful degree of valve margin disruption (Girin et al., 2010). Whilst wheat has been cultivated for thousands of years, the large scale commercialisation of oilseed rape is a more recent development and, within the genetic diversity of material that exists, some cultivars exhibit a greater resistance to pod shatter than commercial varieties (Morgan et al., 1998). This diversity provides an extensive genetic pool that can be investigated and should aid the identification of better mechanisms for successfully controlling pod dehiscence.

\subsection{Seed abscission}

For seed dispersal to take place, not only does the pod have to 'unzip', but the seed must also detach from the funiculus. Like dehiscence, the regulation of seed abscission is a highly co-ordinated event culminating in wall dissolution at the hilum. Work on Arabidopsis has shown that HECATE3 (HEC3), which directs the expression of ADPG1 in the seed abscission zone, and SEEDSTICK (STK) are required for normal seed shedding (Pinyopich et al., 2003; Ogawa et al., 2009).. This aspect of plant development provides a further avenue for manipulating and potentially co-ordinating crop yield.

\subsection{Hormonal regulation of dehiscence and seed abscission}



abscission has been documented extensively, with ethylene promoting and auxin inhibiting the process (Sexton \& Roberts, 1982). Although a peak in ethylene production has been shown to precede dehiscence, exposure to the gas does not hasten pod shatter (Meakin \& Roberts, 1990). Changes in auxin levels during pod development have also been identified but it is not clear to what extent the hormone regulates the dehiscence process (JohnsonFlanagan \& Spencer, 1994; Chauvaux et al., 1997; Child et al., 1998). A recent publication (Sorefan et al., 2009) demonstrated that local changes in pod auxin concentration are crucial for the differentiation of the DZ. The local auxin minimum generated at the valve margins seems to be produced by IND which acts to regulate auxin transport and as such increasing indole-3-acetic acid (IAA) levels at the valve margin leads to the development of an indehiscent phenotype due to the absence of this cell layer (Sorefan et al., 2009). A recent publication by Arnaud et al. (2010) showed that gibberellin is a direct target, and is absolutely required, for the correct functioning of IND. The same authors concluded that $A L C$ interacts directly with DELLA repressors, which antagonize $A L C$ function but are destabilized by gibberellin. Taken together, these findings show that the gibberellin/DELLA pathway has a key role in patterning the Arabidopsis fruit and its eventual dehiscence. gas may only accelerate the onset of senescence rather than promote dehiscence per se (John et al., 1995). This is highlighted by examining parthenocarpic pods which also produce a peak in ethylene and undergo shatter, albeit at a delayed rate, indicating that the pod wall has the capacity to produce the gas (Meakin \& Roberts, 1990; Child et al., 1998). The Arabidopsis protein AtTRP1, an orthologue of a tomato protein which interacts with the tomato ethylene receptors LeETR1 and NR, is highly expressed in the seed abscission zone 
462 (Lin et al., 2009). This observation suggests a possible role for AtTRP1 in regulating seed shedding which could be tested in lines where the gene is silenced or over-expressed.

\section{The Role of Plant Phytohormones in Pod Development}

\subsubsection{The influence of salicylic acid on seed yield}

Plant phytohormones function in many aspects of development including cell

differentiation, elongation, pattern formation and coping with abiotic and biotic stresses, all developmental stage phytohormones can either act synergistically or antagonistically towards one other which, in addition to pleiotropic effects, make their roles in pod and seed development difficult to discern.

Phytohormones can directly influence yield, for instance decreasing salicylic acid

(SA) levels in Arabidopsis $N a h G$ transgenic lines and sid2 mutants increases both the number of seeds per pod and the number of pods per plant, the latter resulting from an enhanced branching phenotype (Abreu \& Munné-Bosch, 2009). Such physiological alterations were also correlated with a change in seed composition whereby $\mathrm{N}$, vitamin $\mathrm{E}$ and pro-vitamin $\mathrm{A}$ content were enriched. This increase is a likely consequence of the late flowering and delayed senescent phenotype associated with SA deficient plants, thus enabling a longer period for resource translocation into the developing seeds (Martinez et al., 2004; Abreu \& MunnéBosch, 2009). Such findings complement other studies which demonstrate that the constitutive overproduction of SA reduces seed yield (Mauch et al., 2001). A decrease in seed weight was however reported in plants with reduced SA abundance (Abreu \& MunnéBosch, 2009) and, since germination potential was never measured, it is unknown how these altered ratios of nutritional compounds in the seed affect viability. Despite the implications for improving crop yield the effects of manipulating SA levels are not fully understood and, 
in light of the fact that exogenous application increased seed yield in a grass species (Joaquin et al., 2007), in contrast to the findings in Arabidopsis, this highlights a potentially species specific role for SA. In addition to this SA has a fundamental role in plant defence against microbial pathogen attack (reviewed in Vlot et al., 2009) and environmental stresses (reviewed in Horváth et al., 2007), hence complete KOs are unlikely to be commercially viable. Nevertheless, SA knockout lines that are regulated by a pod-specific promoter might extend the pod developmental period and allow more resource reallocation into the seeds, without compromising innate resistance strategies.

\subsubsection{Ethylene mutants}

Since the discovery of ethylene as a biologically active and readily diffusible plant growth regulator (Neljubov, 1901) it has been associated with many processes including, but not restricted to, seed germination, growth, timing of organ senescence, fruit ripening and abscission (Abeles et al., 1992). Ethylene can temporally and spatially regulate numerous aspects of plant development, with fleshy and dehiscent fruits becoming more competent to respond to ethylene ripening signals as they age (Joaquin et al., 2007). For instance a burst in seed ethylene production correlates with the onset of pod dehiscence (Oeller et al., 1991), highlighting the importance of ethylene in regulating the timing of developmental events, even if it is not necessarily inducing such responses. The interaction between different hormone pathways remains largely undiscovered, although ethylene is currently known to assist in plant responses to JA, SA, auxin ABA and cytokinin signalling and together they

507 play an important role in responding to biotic and abiotic stresses. This has led to considerable effort being invested in uncovering the ethylene response pathway (for reviews see Ecker \& Stepanova, 2000; Guo \& Ecker, 2004) with recent studies focusing on the mechanisms of sensing and reacting to ethylene signals through a family of cell surface receptors. Arabidopsis has five ethylene receptors (encoded by ERS1, ERS2, ETR1, ETR2 and 
512 EIN4) and mutations conferring dominant ethylene insensitivity all occur in the hydrophobic

513 regions of the $\mathrm{N}$-terminal ethylene sensor domain (Bleecker et al., 1988; Hua et al., 1995;

514 Ecker et al., 1998), implying that there are only a limited number of genetic locations in

515 which mutations are capable of causing ethylene insensitivity (Bleecker et al., 1998). The fact

516 that ethylene receptor mutants have subtly altered phenotypes and encode distinct proteins

517 implies a functional specificity for the different receptors. This view was upheld by Zhou et

518 al. (2007) who argued that they are not functionally redundant but, as previously suggested,

519 may mediate the response of more than one signal (Bleecker et al., 1998). For instance a link

520 between glucose sensitivity and the ethylene pathway (Zhou et al., 1998) has been made

521 since glucose acts to decrease EIN3 levels (Yanagisawa et al., 2003), whilst in the monocot

522 rice it has been shown that reduced expression of the ethylene receptor ETR2 can increase

523 thousand grain weight by up to $4 \%$ through altering starch acclimation and increasing sugar

524 translocation into the filling grains (Wuriyanghan et al., 2009). The ethylene insensitive

525 receptor mutant etrl-1 demonstrates a retarded leaf senescence phenotype which corresponds

526 to a delay in the expression of other senescence associated genes (SAGs). However, this

527 extended visual longevity does not correlate with functionality of the photosynthetic

528 apparatus, so etrl-1 leaves have entered into the senescence programme despite retaining

529 higher chlorophyll levels for longer (Grbic \& Bleecker, 1995), potentially indicating that

530 etr1-1 mutants are unlikely to positively affect seed yield.

531 Examination of microarray data for Arabidopsis (Table 1; developmental data from

532 Wagstaff et al., 2009; wound response data taken from Naomab, 2008) revealed that the only 533 ethylene receptor showing at least a doubling of transcript levels during developmental pod

534 wall senescence was ETR2 which increased 2.8-fold from mature green to yellow senescent

535 pod walls. This gene did not produce any signal on the wounded tissue arrays, indicating that

536 it does not have a role in the wound response at the transcriptional level; the same could be 
said for EIN4 but to a lesser extent. ERS1 and ERS2 were up-regulated 1.9-fold and 1.5-fold respectively in wild type pods $90 \mathrm{~min}$ after wounding the intact pods multiple times with a pin, although only ERS1 showed any developmental response, perhaps indicating that there is a segregation of ethylene receptors with respect to the signals they respond to. Most $A C C$ Synthase (ACS) and ACC Oxidase (ACO) genes present in the Arabidopsis genome did not produce a signal on the microarrays, indicating that the process of ethylene biosynthesis is regulated at the post-transcriptional level. The exception was ACO4 which was 19-fold upregulated during developmental senescence and 11.4-fold increased 90 minutes after wounding. In contrast, ACS2 does not appear to change during developmental senescence but it was 4.7 -fold induced by the wound signal. Wounding also increased expression of genes encoding sugar transporters/signalling molecules, although these did not change during senescence. The glucose transporter GPT1, the hexokinase glucose sensor $H X K 1$, SUC2, SUC3, SUC4 and SUC5 were all up-regulated by wounding. Of these SUC2 increases the most (8-fold) within the 90 minute response period. It would appear therefore, that developmentally programmed resource allocation is regulated slightly differently to resource re-allocation that occurs after an unexpected event such as wounding which will compromise the viability of the seeds within that pod. Ethylene appears to have a stronger association with the wound response, despite its traditional links with the senescence process in other plant organs, and genes encoding sugar transporters within the pod only appear to be up-regulated after wounding, indicating that they may be more involved with resource export than import.

\subsection{A role for $A B A$ in seed development}

Abscisic acid (ABA) is traditionally associated with stress responses, and consequentially growth retardation, but in the absence of such environmental insults it is required for normal seed maturation and is able to promote cellular growth, including in the 
562 pod (Cheng et al., 2002). In wheat the ABA:ethylene ratio affects the rate of grain filling and,

563 since this is quite sensitive, imposing a small stress such as mild drought amplifies ABA

564 levels within wheat grains and correlates with an increase in grain filling (Yang et al., 2006).

565 Similar results have been observed in oilseed rape (B. napus) and Medicago truncatula where

566 raised ABA levels induced by osmotic stress stimulated a higher production of SSP

567 transcripts and accumulation of free amino acids respectively (Wilen et al., 1990; Planchet $e t$

568 al., 2010). Plant sensitivity to ABA is controlled by $A B I 3$, which in turn is required for the

569 accumulation of SSPs within the seed (Nambara et al., 1992). Whilst the oilseed rape

570 experiments described above were performed on excised embryos, it does suggest that a

571 controlled application of ABA to the pods may increase the abundance of SSPs in the seeds

572 without the need to implement a water stress.

5736.3 A role for other phytohormones

574

Gibberellins (GAs) are another class of phytohormone that have numerous functions

within the plant including helping to break seed dormancy, regulating plant growth and floral induction. In Arabidopsis normal pod development requires GA levels to be kept within a confined range, as increased concentrations result in fewer seeds per pod (Rieu et al., 2008) and a decrease in pod wall length and weight (Srinivasan \& Morgan, 1996). Correlations between GA and cytokinin levels also appear crucial for regulating pod wall growth (Srinivasan \& Morgan, 1996). Fertilisation triggers an auxin-mediated promotion of GA synthesis specifically in the ovule which is then transported to the valves where GA targets DELLA proteins for degradation and therefore releases the repression of fruit growth seen in unfertilised pods (Marti et al., 2007; Dorcey et al., 2009). levels and it is capable of functioning like a hormonal signalling molecule by indicating the plant's nutrient status (Arenas-Huertero et al., 2000; Cheng et al., 2002; Rolland et al., 2002). 
587 For instance, there are interactions between sugar and nitrogen signalling that can affect the 588 carbon-nitrogen balance, (Sheen et al., 1999), indicating that the capacity of a plant to sense 589 changes in the glucose concentration within individual organs can regulate phytohormone 590 production and consequentially mediate the source-sink nutrient balance (Cheng et al., 2002).

591 This theory is further supported by the observation that the Arabidopsis glucose

592 insensitive/ABA-deficient mutant ginl/aba2 has smaller pods than wild type and 593 consequentially produces far more aborted embryos per pod than wild type, although any mature seeds are the normal size (Cheng et al., 2002).

\subsection{Altering the developmental period}

Cytokinins help to regulate the timing of senescence and, since their levels fall at the onset of this process, exogenous application can delay senescence (Nooden et al., 1979). This knowledge has enabled leaf senescence to be postponed by attaching a promoter from the senescence specific gene $S A G 12$ to the gene encoding isopentyl transferase (IPT), which catalyses cytokinin biosynthesis, generating auto-inhibition of senescence through the maintenance of pre-senescence cytokinin levels. In tobacco this prolonged the flowering period and photosynthetic lifespan which together resulted in a 50\% increase in dry weight and seed yield, although it was not reported whether this also affected seed composition (Gan \& Amasino, 1995). However, the SAG12:IPT construct in wheat only resulted in delayed senescence and not an increase in seed yield which the authors suggested was due to interference by the construct with the normally extremely rapid relocation of resources from senescing leaves to reproductive sinks (Sýkorová et al., 2008). The tight correlation between developmental period and seed yield raises the possibility that a similar system of autoregulation of senescence could be implemented to co-ordinate pod development, at least in dicotyledonous plants. Theoretically, delaying senescence and extending the photosynthetic period would increase the potential for seed filling and prevent the onset of dehiscence. The 
612 process of senescence and dehiscence could subsequently be coordinated across the whole 613 plant if the inhibition provided by cytokinin could be turned off in a controlled manner, for example by using an inducible promoter system.

615

\section{Silique biosynthesis of compounds for the seed}

\subsection{Silique and seed photosynthesis}

Since the onset of leaf senescence occurs prior to the last pod forming, and before seed fill is complete, embryos have to rely upon pod or seed wall and stem photosynthesis to generate the remainder of their photoassimilates required for viable seed production.

Enclosure within a pod limits the photosynthetic capacity of the seed itself; in contrast the pod has a photosynthetic potential far greater than that of a leaf if assessed on the assimilate produced per unit of chlorophyll basis (King et al., 1997). Carbon photosynthates stored within the pod wall are thought to be remobilised to developing seeds as a decrease in hexose levels corresponds with a concomitant increase in seed growth (King et al., 1997).

Additionally de novo starch synthesis within oilseeds is presumed to be insufficient to account for the final oil levels observed, indicating the importance of translocating carbohydrates, such as sucrose and hexose, across the pod wall. To enable seeds to generate some of their own photoassimilates the pod wall in oilseed rape has a sclerencyma cell layer nearest to the inner pod cavity that is predicted to act as a barrier to gas diffusion and therefore aid a build-up of $\mathrm{CO}_{2}$ around the seeds (King et al., 1998). Developing seeds are capable of fixing this $\mathrm{CO}_{2}$ and consequentially generating energy for the synthesis of seed storage products, although predictions suggest that the quantity of $\mathrm{CO}_{2}$ is not enough to sustain photosynthesis in the seed itself. In the pea pod, for example, it has been calculated that respiration accounts for the loss of more $\mathrm{C}$ than is incorporated into the fruit during the photosynthetic period. In the second half of seed development the pod is only capable of 
637

638

639

640

641

642

643

644

645

646

647

648

649

650

651

652

653

654

655

656

657

658

659

660

661

producing about $10 \%$ of the carbon required by the seed (Flinn et al., 1977) most likely due to onset of chlorophyll catabolism in the pod wall, but this reinforces the absolute necessity to re-allocate resources around the plant.

\subsubsection{Seed storage proteins}

SSPs accumulate within both protein storage vacuoles and the endoplasmic reticulum (Crofts et al., 2004). During the seed filling phase the import of amino acids into the embryo only occurs via the phloem and requires the amino acid co-transporter located within the pod vascular system that is encoded by AAP2 (Hirner et al., 1998). AAP2 might therefore have an important role in transporting amino acids from vegetative plant organs and the pod wall into the seed. Should it emerge that SSP transcripts found in the pod wall (Wagstaff et al., 2009) are transcribed into proteins which are subsequently translocated to the seeds $A A P 2$ might be involved in their transport. This leads to the possibility that targeting pod wall transcripts could increase the concentration of nutritionally essential sulphur proteins normally lacking within oil seeds.

\subsubsection{Synthesising molecules in the pod wall}

A microarray analysis in B. napus revealed that seeds express genes encoding many essential storage compounds (Yu et al., 2010). This finding does not automatically signify that all these genes were translated into proteins in situ but it does indicate that the seed does not necessarily need to import them from the pod wall. This needs to be weighed against the observation that, despite seeds containing the enzymes for synthesising some of their own compounds such as glucosinolates, they are still produced in the pod wall and translocated into the developing embryos (Bilsborrow et al., 1993; Zhao et al., 1993; Du \& Halkier, 1998). The reasons for a plant utilising this strategy is unclear; energetically it would be more efficient for the seeds to synthesise their own storage compounds so the factors that determine whether the seeds, pod wall, or both, translate these remain to be elucidated. 


\subsection{Lipids and oils}

At higher light intensities seeds are capable of synthesising more fatty acids, indicating that an increased rate of photosynthesis might be responsible for this (Schwender et al., 2004; Goffman et al., 2005). Therefore it follows that either making the pod walls thinner to improve light penetration, or providing the seeds with more energy, could improve oil synthesis. This topic is laced with controversy, for whilst Eastmond et al. (1996) believes that the low level of incident light reaching a seed is insufficient to generate enough reducing power in the form of NADPH for lipid biosynthesis, two independent studies (Willms et al., 1999; Schwender et al., 2004) refute this claim. Instead both support the notion that green oilseeds are well adapted to low light levels and as such can produce enough energy for fatty acid synthesis. Regardless of who is correct, the implication of this is that an increased oil content could be achieved by having seeds and or pod walls which remained photosynthetically active for longer, potentially by utilising the SAG12:IPT auto-regulation system discussed above or a stay green phenotype which remains functionally photosynthetic and has delayed senescence.

\subsection{Translocation of molecules from the pod wall into the developing seeds}

The transport of molecules from the pod wall into the seeds represents a centripedal mode of transport towards the inner integuments of the pod presumably via the single entry point at the base of the pod in the vascular system. Seeds of the legume species Medicago truncatula are highly specialised for the importation of nutrients with their micropylar region containing a vascular system organised into tracheids (Abirached-Darmency et al., 2005). The presence of sucrose synthase (SUS) in phloem associated companion cells (Fallahi et al., 2008) when the siliques are fully mature supports the previously identified role of SUS in phloem loading/unloading (Martin et al., 1993; Nolte \& Koch, 1993). It is predicted that SUS could be vital for transporting assimilates generated in the pod wall into developing seeds via 
the pod wall phloem (Fallahi et al., 2008) especially since the SUS protein exhibits a spatial change throughout development. Initially SUS is highly expressed within the pod wall and funiculus, but by the later stages of development it is only found in the embryo and aleurone layer of the seed (Fallahi et al., 2008), indicating a translocation of assimilates from the pod wall into the seeds via the phloem tissue.

692

\section{Conclusion}

This review has highlighted the contributions that a pod can make to the development of the encapsulated seed and identified strategies for manipulating resource allocation (summarised in Figure 2). In addition to providing protection from biotic and abiotic stresses it is evident that the photosynthetically active pod can contribute assimilates and nutrients that are subsequently imported into the developing seeds and a 'push-pull' model is proposed where the strength of the sink exerted by the seeds determines the degree to which resources are remobilised from other parts of the plant. Transcript profiling of the pod wall during development has revealed that the tissue shares features in common with leaf material and it is possible that shared events take place during pod and leaf senescence. Manipulation of the timing of pod senescence may make it possible to enhance the duration of grain filling and increase protein, carbohydrate or lipid content into the developing seed. In weed species, such as Arabidopsis, the partitioning of assimilates is highly co-ordinated within a pod so that at dehiscence all seeds are at an equivalent stage of maturation; although the timing of dehiscence across the plant, or a population of plants, is generally uncoordinated so that pods release their contents over a long period of time. In domesticated crops, such as peas and beans, grain filling may be less well orchestrated within a pod or an ear, and some seeds may act a stronger sinks than others. In contrast, coordination across the whole plant, and between

711 plants in a monoculture, is extremely good as a consequence of the strong selection imposed 
712 by man for uniformity as crops have been domesticated. The mechanism that co-ordinates

713 assimilate import into seeds positioned at different sites in a pod is unclear. However, recent

714 transcriptional analyses in Arabidopsis has identified a response regulator, ARR22, expressed

715 within the micropylar tissues, that plays a key role in regulating the response of seeds to

716 wounding and could contribute to regulating the assimilate import/export. Further 'omic

717 analyses of pod tissues, particularly those of the pod wall, will assist in dissecting the

718 contribution of the pod to the development of the seed. Armed with this information it

719 should be possible to devise strategies to manipulate pod development so that we can not

720 only enhance seed yield but also, and perhaps even more importantly, its nutritional value. 
References

723

Aach H, Heise K. 1998. On the compartmentation of triacylglycerol synthesis in developing seeds of Brassica napus. Botanica Acta 111: 123-129.

Abeles F, Morgan P, Saltveit M. 1992. Ethylene in Plant Biology: Academic Press San Diego (USA).

Abirached-Darmency M, Abdel-gawwad MR, Conejero G, Verdeil JL, Thompson R. 2005. In situ expression of two storage protein genes in relation to histo-differentiation at midembryogenesis in Medicago truncatula and Pisum sativum seeds. Journal of Experimental Botany 56: 2019-2028.

Abreu ME, Munné-Bosch S. 2009. Salicylic acid deficiency in $N a h G$ transgenic lines and sid2 mutants increases seed yield in the annual plant Arabidopsis thaliana. Journal of Experimental Botany 60: 1261-1271.

Allen EJ, Morgan DG. 1972. A quantitative analysis of the effects of nitrogen on the growth, development and yield of oilseed rape. The Journal of Agricultural Science 78: 315-324.

Archetti M, Döring TF, Hagen SB, Hughes NM, Leather SR, Lee DW, Lev-Yadun S, Manetas Y, Ougham HJ, Schaberg PG, Thomas H. 2009. Unravelling the evolution of autumn colours: an interdisciplinary approach. Trends in Ecology \& Evolution 24: 166-173.

Arenas-Huertero F, Arroyo A, Zhou L, Sheen J, Leo P. 2000. Analysis of Arabidopsis glucose insensitive mutants, gin5 and gin6, reveals a central role of the plant hormone ABA in the regulation of plant vegetative development by sugar. Genes \& Development 14: 2085-2096.

Arnaud N, Girin T, Sorefan K, Fuentes S, Wood TA, Lawrenson T, Sablowski R, Østergaard L. 2010. Gibberellins control fruit patterning in Arabidopsis thaliana. Genes and Development 24: 2127-2132.

Awazuhara M, Fujiwara T, Hayashi H, Watanabe-Takahashi A, Takahashi H, Saito K. 2005. The function of SULTR2;1 sulfate transporter during seed development in Arabidopsis thaliana. Physiologia Plantarum 125: 95-105. 
Bilsborrow PE, Evans EJ, Murray F, Zhao FJ. 1993. Glucosinolate changes in developing pods of single and double low varieties of autumn-sown oilseed rape (B. napus). Annals of Applied Biology 122: 135-143.

Bleecker AB, Esch JJ, Hall AE, Rodríguez FI, Binder BM. 1998. The ethylene-receptor family from Arabidopsis: structure and function. Philosophical Transactions of the Royal Society of London. Series B, Biological Sciences 353: 1405-1412.

Bleecker AB, Estelle MA, Somerville C, Kende H. 1988. Insensitivity to ethylene conferred by a dominant mutation in Arabidopsis thaliana. Science 241: 1086-1089.

\section{Borthwick HA, Hendricks SB, Parker MW, Toole EH, Toole VK. 1951. A reversible} photoreaction controlling seed germination. Proceedings of the National Academy of Sciences 38: $662-666$.

Buchanan-Wollaston V, Ainsworth C. 1997. Leaf senescence in Brassica napus: cloning of senescence related genes by subtractive hybridisation. Plant Molecular Biology 33: 821-834.

Buchanan-Wollaston V. 1997. The molecular biology of leaf senescence. Journal of Experimental Botany 48: 181-199.

Chauvaux N, Child R, John K, Ulvskov P, Borkhardt B, Prinsen E, Van Onckelen HA. 1997. The role of auxin in cell separation in the dehiscence zone of oilseed rape pods. Journal of Experimental Botany 48: 1423-1429.

Cheng W-H, Endo A, Zhou L, Penney J, Chen H-C, Arroyo A, Leon P, Nambara E, Asami T, Seo M, Koshiba T, Sheen J. 2002. A unique short-chain dehydrogenase / reductase in Arabidopsis glucose signaling and abscisic acid biosynthesis and function. The Plant Cell 14: 2723-2743.

Child RD, Chauvaux N, John K, Ulvskov P, Van Onckelen HA. 1998. Ethylene biosynthesis in oilseed rape pods in relation to pod shatter. Journal of Experimental Botany 49: 829-838.

Chopin F, Orsel M, Dorbe MF, Chardon F, Truong HN, Miller AJ, Krapp A, Daniel-Vedele F. 2007. The Arabidopsis ATNRT2.7 nitrate transporter controls nitrate content in seeds. Plant Cell 19: 1590-1602. 
Claessens M, van Baak MA, Monsheimer S, Saris WHM. 2009. The effect of a low fat, high protein or high carbohydrate ad libitum diet on weight loss maintenance and metabolic risk factors. International Journal of Obesity 33: 296-304.

Crofts AJ, Washida H, Okita TW, Ogawa M, Kumamaru T. 2004. Targeting of proteins to endoplasmic reticulum-derived compartments in plants. The importance of RNA localization. Plant Physiology 136: 3414-3419.

Davies GC, Bruce DM. 1997. Fracture mechanics of oilseed rape pods. Journal of Materials Science 32: $5895-5899$.

Diepenbrock W. 2000. Yield analysis of winter oilseed rape (Brassica napus L.): a review. Field Crops Research 67: 35-49.

Dorcey E, Urbez C, Blázquez MA, Carbonell J, Perez-Amador MA. 2009. Fertilization-dependent auxin response in ovules triggers fruit development through the modulation of gibberellin metabolism in Arabidopsis. Plant Journal 58: 318-332.

Du LC, Halkier BA. 1998. Biosynthesis of glucosinolates in the developing silique walls and seeds of Sinapis alba. Phytochemistry 48: 1145-1150.

Eastmond P, Koláčá L, Rawsthorne S. 1996. Photosynthesis by developing embryos of oilseed rape (Brassica napus L.). Journal of Experimental Botany 47: 1763-1769.

Ecker JR, Hua J, Sakai H, Nourizadeh S, Chen QG, Bleecker AB, Meyerowitz EM. 1998. EIN4 and ERS2 are members of the putative ethylene receptor gene family in Arabidopsis. The Plant Cell 10: 1321.

Ecker JR, Stepanova AN. 2000. Ethylene signaling: from mutants to molecules. Current Opinion in Plant Biology 3: 353-360.

Fallahi H, Scofield GN, Badger MR, Chow WS, Furbank RT, Ruan Y-L. 2008. Localization of sucrose synthase in developing seed and siliques of Arabidopsis thaliana reveals diverse roles for SUS during development. Journal of Experimental Botany 59: 3283-3295.

Fan S-C, Lin C-S, Hsu P-K, Lin S-H, Tsay Y-F. 2009. The Arabidopsis nitrate transporter NRT1.7, expressed in phloem, is responsible for source-to-sink remobilization of nitrate. The Plant Cell 21: 2750-2761. 
Feller U, Fischer A. 1994. Nitrogen metabolism in senescing leaves. Critical Reviews in Plant Science 13: 241-273.

Ferrándiz C. 2002. Regulation of fruit dehiscence in Arabidopsis. Journal of Experimental Botany 53: $2031-2038$.

Ferrándiz C. 2000. Negative regulation of the SHATTERPROOF Genes by FRUITFULL during Arabidopsis fruit development. Science 289: 436-438.

Ferrándiz C, Pelaz S, Yanofsky MF. 1999. Control of carpel and fruit development in Arabidopsis. Annual Review of Biochemistry 68: 321-354.

Flanagan CA, Hu Y, Ma H 1996. Specific regulation of the AGL1 MADS-box gene suggests regulatory functions in Arabidopsis gynoecium and ovule development. The Plant Journal. 10: $343-353$.

Flinn AM, Atkins Ca, Pate JS. 1977. Significance of photosynthetic and respiratory exchanges in the carbon economy of the developing pea fruit. Plant Physiology 60: 412-418.

Fuhrmann J, Johnen T, Heise KP. 1994. Compartmentation of fatty acid metabolism in zygotic rape embryos. Journal of Plant Physiology 143: 565-569.

Gammelvind L, Schjoerring J, Mogensen V, Jensen C, Bock J. 1996. Photosynthesis in leaves and siliques of winter oilseed rape (Brassica napus L). Plant and Soil 186: 227-236.

Gan S, Amasino RM. 1995. Inhibition of leaf senescence by autoregulated production of cytokinin. Science 270: 1986-1988.

Gattolin S, Alandete-Saez M, Elliott K, Gonzalez-Carranza Z, Naomab E, Powell C, Roberts JA. 2006. Spatial and temporal expression of the response regulators $A R R 22$ and $A R R 24$ in Arabidopsis thaliana. Journal of Experimental Botany 57: 4225-4233.

Girin T, Stephenson P, Goldsack CM, Kempin SA, Perez A, Pires N, Sparrow PA, Wood TA, Yanofsky MF, Ostergaard L. 2010. Brassicaceae INDEHISCENT genes specify valve margin cell fate and repress replum formation. Plant Journal 63: 329-338.

Goffman FD, Alonso AP, Schwender J, Shachar-Hill Y, Ohlrogge JB. 2005. Light enables a very high efficiency of carbon storage in developing embryos of rapeseed. Plant Physiology 138: 2269-2279. 
Grbic V, Bleecker AB. 1995. Ethylene regulates the timing of leaf senescence in Arabidopsis. Plant Journal 8: 595-602.

Groszmann M, Bylstra Y, Lampugnani ER, Smyth DR. 2010. Regulation of tissue-specific expression of SPATULA, a bHLH gene involved in carpel development, seedling germination, and lateral organ growth in Arabidopsis. Journal of Experimental Botany 61: 1495-1508.

Gu Q, Ferrándiz C, Yanofsky MF, Martienssen R. 1998. The FRUITFULL MADS-box gene mediates cell differentiation during Arabidopsis fruit development. Development 125: 15091517.

Guo H, Ecker JR. 2004. The ethylene signaling pathway: new insights. Current Opinion in Plant Biology 7: 40-49.

Harvey D. 1973. The Translocation of 14C-photosynthate in Pisum sativum L. Annuals of Botany 37: 787-794.

Heisler MG, Atkinson a, Bylstra YH, Walsh R, Smyth DR. 2001. SPATULA, a gene that controls development of carpel margin tissues in Arabidopsis, encodes a bHLH protein. Development 128: $1089-1098$.

Herman EM, Larkins BA. 1999. Protein storage bodies and vacuoles. Plant Cell 11: 601-613.

Hirner B, Fischer WN, Rentsch D, Kwart M, Frommer WB. 1998. Developmental control of $\mathrm{H}+/$ amino acid permease gene expression during seed development of Arabidopsis. Plant Journal 14: 535-544.

Hoch Wa, Zeldin EL, McCown BH. 2001. Physiological significance of anthocyanins during autumnal leaf senescence. Tree Physiology 21: 1-8.

\section{Horak J, Grefen C, Berendzen KW, Hahn A, Stierhof YD, Stadelhofer B, Stahl M, Koncz C,} Harter K. 2008. The Arabidopsis thaliana response regulator ARR22 is a putative AHP phospho-histidine phosphatase expressed in the chalaza of developing seeds. BMC Plant Biology 8: 77.

Horváth E, Szalai G, Janda T. 2007. Induction of abiotic stress tolerance by salicylic acid signaling. Journal of Plant Growth Regulation 26: 290-300. 
Hua J, Chang C, Sun Q, Meyerowitz EM. 1995. Ethylene insensitivity conferred by Arabidopsis ERS gene. Science 269: 1712-1714.

Joaquin TBM, Trejo C, Hernandez-Garay A, Perez PJ, Garcia ADG, Quero CAR. 2007. Effects of ethephon, salicylic acid and cidef-4 on the yield and quality of guinea grass seed. Tropical Grasslands 41: 55-60.

John I, Drake R, Farrell A, Cooper W, Lee P, Horton P, Grierson D. 1995. Delayed leaf senescence in ethylene deficient acc-oxidase antisense tomato plants - molecular and physiological analysis. Plant Journal 7: 483-490.

Johnson-Flanagan AM, Spencer MS. 1994. Ethylene production during development of mustard (Brassica juncea) and canola (Brassica napus) seed. Plant Physiology 106: 601-606.

King SP, Badger MR, Furbank RT. 1998. CO2 refixation characteristics of developing canola seeds and silique wall. Australian Journal of Plant Physiology 25: 377-386.

King SP, Lunn JE, Furbank RT. 1997. Carbohydrate content and enzyme metabolism in developing canola siliques. Plant Physiology 114: 153-160.

Köhler C, Merkle T, Roby R, Neuhaus G. 2001. Developmentally regulated expression of a cyclic nucleotide-gated ion channel from Arabidopsis indicates its involvement in programmed cell death. Planta 213: 327-332.

Lalonde S, Tegeder M, Throne-Holst M, Frommer WB, Patrick JW. 2003. Phloem loading and unloading of sugars and amino acids. Plant, Cell and Environment 26: 37-56.

Liljegren SJ, Ditta GS, Eshed HY, Savidge B, Bowman JL, Yanofsky MF. 2000. SHATTERPROOF MADS-box genes control seed dispersal in Arabidopsis. Nature 404: 766770.

Liljegren SJ, Roeder AHK, Kempin Sa, Gremski K, Østergaard L, Guimil S, Reyes DK, Yanofsky MF. 2004. Control of fruit patterning in Arabidopsis by INDEHISCENT. Cell 116: 843-853.

Lin ZF, Ho CW, Grierson D. 2009. AtTRPl encodes a novel TPR protein that interacts with the ethylene receptor ERS1 and modulates development in Arabidopsis. Journal of Experimental Botany 60: 3697-3714. 
886

887

888

889

890

891

892

893

894

895

896

897

898

899

900

901

902

903

904

905

906

907

908

909

910

911

912

Lindoo SJ, Nooden LD. 1976. The interrelation of fruit development and leaf senescence in ' Anoka ' soybeans. Science 137: 218-223.

Lindoo SJ, Nooden LD. 1977. On the behavior of the senescence signal in Anoka soybeans'. Experimental Biology: 1136-1140.

Lockhart Ja, Gottschall V. 1961. Fruit-induced \& apical senescence in Pisum sativum L. Plant Physiology 36: 389-398.

Louvet R, Cavel E, Gutierrez L, Guenin S, Roger D, Gillet F, Guerineau F, Pelloux J. 2006. Comprehensive expression profiling of the pectin methylesterase gene family during silique development in Arabidopsis thaliana. Planta 224: 782-791.

Ma L, Sun N, Liu X, Jiao Y, Zhao H, Deng XW. 2005. Organ-specific expression of Arabidopsis genome during development. Plant Physiology 138: 80-91.

MacLeod J. 1981. Harvesting in oilseed rape. Oilseed Rape Book. A manual for growers, farmers and advisors (Green, C., ed.). Cambridge: Cambridge Agricultural Publishing: 107-120.

Mandal S, Mandal RK. 2000. Seed storage proteins and approaches for improvement of their nutritional quality by genetic engineering. Current Science 79: 576-589.

Marti C, Orzaez D, Ellul P, Moreno V, Carbonell J \& Granell A. 2007. Silencing of DELLA induces facultative parthenocarpy in tomato fruits. Plant Journal. 52: 865-876.

Martin T, Frommer WB, Salanoubat M, Willmitzer L. 1993. Expression of an Arabidopsis sucrose synthase gene indicates a role in metabolization of sucrose both during phloem loading and sink organs. The Plant Journal 4: 367-377.

Martinez C, Pons E, Prats G, Leon J. 2004. Salicylic acid regulates flowering time and links defence responses and reproductive development. The Plant Journal 37: 209-217.

Mauch F, Mauch-Mani B, Gaille C, Kull B, Haas D, Reimmann C. 2001. Manipulation of salicylate content in Arabidopsis thaliana by the expression of an engineered bacterial salicylate synthase. The Plant Journal 25: 67-77.

McIntyre G. 1997. The Role of nitrate in the osmotic and nutritional control of plant development. Australian Journal of Plant Physiology 24: 103-118. 
Meakin PJ, Roberts JA. 1990. Dehiscence of fruit in oilseed rape (Brassica napus L.). Journal of Experimental Botany 41: 1003-1011.

Morgan CL, Bruce DM, Child R, Ladbrooke ZL, Arthur AE. 1998. Genetic variation for pod shatter resistance among lines of oilseed rape developed from synthetic B. napus. Field Crops Research 58: 153-165.

Morgan CL, Ladbrooke ZL, Bruce DM, Child R, Arthur AE. 2000. Breeding oilseed rape for pod shattering resistance. Journal of Agricultural Science 135: 347-359.

Musgrave M, Allen J, Blasiak J, Tuominen L, Kuang A. 2008. In vitro seed maturation in Brassica rapa L.: Relationship of silique atmosphere to storage reserve deposition. Environmental and Experimental Botany 62: 247-253.

Nambara E, Naito S, McCourt P. 1992. A mutant of Arabidopsis which is defective in seed development and storage protein accumulation is a new ABI3 allele. The Plant Journal 2: $435-441$.

Naomab E. 2008. The role of response regulators during Arabidopsis pod development. University of Nottingham Thesis.

Neljubov D. 1901. Uber die horizontale nutation der stengel von Pisum sativum und einiger anderer. Pflanzen Beitrage und Botanik Zentralblatt. 10: 128-139

Nolte KD, Koch KE. 1993. Companion-cell specific localization of sucrose synthase in zones of phloem loading and unloading. Plant Physiology 101: 899-905.

Nooden LD, Kahanak GM, Okatan Y. 1979. Prevention of monocarpic senescence in soybeans with auxin and cytokinin: an antidote for self-destruction. Science 206: 841-843.

Nooden LD, Murray BJ. 1982. Transmission of the monocarpic senescence signal via the xylem in soybean. Plant Physiology 69: 754-756.

Nooden LD, Penney JP. 2001. Correlative controls of senescence and plant death in Arabidopsis thaliana (Brassicaceae). Journal of Experimental Botany 52: 2151-2159.

Nooden LD, Rupp DC, Derman BD. 1978. Seraration of seed development from monocarpic senescence in soybeans. Nature 271: 354-357. 
Oeller PW, Min-wong L, Taylor LP, Pike DA, Athanasios T. 1991. Reversible Inhibition of Tomato antisense RNA. Science 437: 5-7.

Ogawa M, Kay P, Wilson S, Swain SM. 2009. Arabidopsis dehiscence zone polygalacturonase1 (ADPG1), ADPG2, and QUARTET2 are polygalacturonases required for cell separation during reproductive development in Arabidopsis. The Plant Cell 21: 216-233.

Okumoto S, Schmidt R, Tegeder M, Fischer WN, Rentsch D, Frommer WB, Koch W. 2002. High affinity amino acid transporters specifically expressed in xylem parenchyma and developing seeds of Arabidopsis. Journal of Biological Chemistry 277: 45338-45346.

Østergaard L, Kempin Sa, Bies D, Klee HJ, Yanofsky MF. 2006. Pod shatter-resistant Brassica fruit produced by ectopic expression of the FRUITFULL gene. Plant Biotechnology Journal 4: $45-51$.

Patrick JW. 1997. Phloem unloading: sieve element unloading and post-sieve element transport. Annual review of Plant Physiology and Plant Molecular Biology 48: 191-222.

Patrick JW, Offler CE. 2001. Compartmentation of transport and transfer events in developing seeds. Journal of Experimental Botany 52: 551-564.

Pechan Pa, Morgan DG. 1985. Defoliation and its effects on pod and seed development in oil seed rape (Brassica napus L.). Journal of Experimental Botany 36: 458-468.

Pinyopich A, Ditta GS, Savidge B, Liljegren SJ, Baumann E, Wisman E, Yanofsky MF. 2003. Assessing the redundancy of MADS-box genes during carpel and ovule development. Nature 424: 85-88.

Planchet E, Rannou1 O, Ricoult C, Boutet-Mercey S, Maia-Grondard A, Limami AM. 2010. Nitrogen metabolism responses to water deficit act through both abscisic acid (ABA) dependent and independent pathways in Medicago truncatula during post-germination. Journal of Experimental Botany: doi: 10.1093/jxb/erq294 online early.

Prakash JS, Baig Ma, Mohanty P. 2001. Senescence induced structural reorganization of thylakoid membranes in Cucumis sativus cotyledons; LHC II involvement in reorganization of thylakoid membranes. Photosynthesis Research 68: 153-161. 
Rajani S, Sundaresan V. 2001. The Arabidopsis myc / bHLH gene ALCATRAZ enables cell separation in fruit dehiscence. Current Biology 11: 1914-1922.

Ramana S, Ghildiyal MC. 1997. Contribution of leaf photosynthesis towards seed yield in Brassica species. Journal of Agronomy and Crop Science 178: 185-187.

\section{Rieu I, Eriksson S, Powers SJ, Gong F, Griffiths J, Woolley L, Benlloch R, Nilsson O, Thomas} SG, Hedden P, Phillips AL. 2008. Genetic analysis reveals that C19-GA 2-oxidation is a major gibberellin inactivation pathway in Arabidopsis. The Plant Cell 20: 2420-2436.

Robinson CK, Hill SA. 1999. Altered resource allocation during seed development in Arabidopsis caused by the abi3 mutation. Plant Cell and Environment 22: 117-123.

Rochat C, Boutin J-P. 1991. Metabolism of phloem-borne amino acids in maternal tissues of fruit of nodulated or nitrate-fed pea plants (Pisum sativum L ). 42: 207-214.

Rochat C, Boutin J-P. 1992. Temporary storage compounds and sucrose-starch metabolism in seed coats during pea seed development (Pisum sativum). Physiologia Plantarum 85: 567-572.

Roeder AHK, Ferra C, Yanofsky MF. 2003. The role of the REPLUMLESS homeodomain protein in patterning the Arabidopsis fruit. Current Biology 13: 1630-1635.

Rolland F, Moore B, Sheen J. 2002. Sugar sensing and signaling in plants. Plant Cell 14: 185-205.

Rossato L, Lainé P, Ourry a. 2001. Nitrogen storage and remobilization in Brassica napus L. during the growth cycle: nitrogen fluxes within the plant and changes in soluble protein patterns. Journal of Experimental Botany 52: 1655-1663.

Ruuska SA, Girke T, Benning C, Ohlrogge JB. 2002. Contrapuntal networks of gene expression during Arabidopsis seed filling. Plant Cell 14: 1191-1206.

Schiltz S, Munier-Jolain N, Jeudy C, Burstin J, Salon C. 2005. Dynamics of exogenous nitrogen partitioning and nitrogen remobilization from vegetative organs in pea revealed by $15 \mathrm{n}$ in vivo labeling throughout seed filling. Plant Physiology 137: 1463-1473.

Schjoerring J, Bock J, Gammelvind L, Jensen C, Mogensen V. 1995. Nitrogen incorporation and remobilization in different shoot components of field-grown winter oilseed rape (Brassica napus L) as affected by rate of nitrogen application and irrigation. Plant and Soil 177: 255264. 
995

996

997

998

999

1000

1001

1002

1003

1004

1005

1006

1007

1008

1009

1010

1011

1012

1013

1014

1015

1016

1017

1018

1019

1020

1021

Schulze W, Schulze E, Stadler J, Heilmeier H, Mooney HA. 1990. Growth and reproduction of Arabidopsis thaliana in relation to storage of starch and nitrate in the wild-type and in starchdeficient and nitrate-uptake-deficient mutants. Environment: 795-809.

Schulze W, Schulze E, Stadler J, Heilmeier H, Stitt M, Mooney H. 1994. Growth and Reproduction of Arabidopsis thaliana in relation to storage of starch and nitrate in the wildtype and in starch deficient and nitrate uptake deficient mutants. Plant Cell and Environment 17: 795-809.

Schwender J, Ruuska SA, Ohlrogge JB. 2004. The capacity of green oilseeds to utilize photosynthesis to drive biosynthetic processes. Plant Physiology 136: 2700-2709.

Scutt CP, Vinauger-Douard M, Fourquin C, Finet C, Dumas C. 2006. An evolutionary perspective on the regulation of carpel development. Journal of Experimental Botany 57: $2143-2152$

Sessions RA, Zambryski PC. 1995. Arabidopsis gynoecium structure in the wild type and in ettin mutants. Development 1532: 1519-1532.

Setter TL, Brun WA. 1980. Stomatal closure and photosynthetic inhibition in soybean leaves induced by petiole girdling and pod removal. Plant Physiology 65: 884-887.

Sexton R, Roberts JA. 1982. Cell Biology of Abscission. Annual Review of Plant Pathology 33: $133-162$.

Sheen J, Zhou L, Jang JC. 1999. Sugars as signaling molecules. Current Opinion in Plant Biology 2: $410-418$

\section{Sýkorová B, Kurešová G, Daskalova S, Trčková M, Hoyerová K, Raimanová I, Motyka V,} Trávníčková A, Elliott MC, Kamínek M. 2008. Senescence-induced ectopic expression of the A. tumefaciens ipt gene in wheat delays leaf senescence, increases cytokinin content, nitrate influx, and nitrate reductase activity, but does not affect grain yield. Journal of Experimental Botany 59: 377-387.

Small E, Brookes B. 1984. Coiling of alfalfa pods in relation to resistance against seed chalcids: additional observations. Canadian Journal of Plant Science 64: 659-665 
Sorefan K, Girin T, Liljegren SJ, Ljung K, Robles P, Galvan-Ampudia CS, Offringa R, Friml J, Yanofsky MF, Ostergaard L. 2009. A regulated auxin minimum is required for seed dispersal in Arabidopsis. Nature 459: 583-586.

Spence J, Vercher Y, Gates P, Harris N. 1996. Pod shatter in Arabidopsis thaliana, Brassica napus and B. juncea. Journal of Microscopy 181: 195-203.

Srinivasan A, Morgan DG. 1996. Growth and development of the pod wall in spring rape (Brassica napus) as related to the presence of seeds and exogenous phytohormones. The Journal of Agricultural Science 127: 487-500.

Stadler R, Lauterbach C, Sauer N. 2005. Cell-to-cell movement of green fluorescent protein reveals post-phloem transport in the outer integument and identifies symplastic domains in Arabidopsis seeds and embryos. Plant Physiology 139: 701-712.

Taylor L, Nunes-Nesi A, Parsley K, Leiss A, Leach G, Coates S, Wingler A, Fernie AR, Hibberd JM. 2010. Cytosolic pyruvate,orthophosphate dikinase functions in nitrogen remobilization during leaf senescence and limits individual seed growth and nitrogen content. The Plant Journal: 641-652.

Van Dongen JT. 2003. Structure of the Developing Pea Seed Coat and the Post-phloem Transport Pathway of Nutrients. Annals of Botany 91: 729-737.

Vlot aC, Dempsey DMA, Klessig DF. 2009. Salicylic Acid, a multifaceted hormone to combat disease. Annual Review of Phytopathology 47: 177-206.

Wagstaff C, Yang TJ, Stead AD, Buchanan-Wollaston V, Roberts JA. 2009. A molecular and structural characterization of senescing Arabidopsis siliques and comparison of transcriptional profiles with senescing petals and leaves. Plant Journal 57: 690-705.

Wardlaw B. 1990. The control of carbon partitioning in plants. New Phytologist 116: 341-381.

Wilen RW, Mandel RM, Pharis RP, Holbrook LA, Moloney MM. 1990. Effects of abscisic acid and high osmoticum on storage protein gene expression in microspore embryos of Brassica napus. Plant Physiology 94: 875-881.

Willms J, Salon C, Layzell D. 1999. Evidence for light-stimulated fatty acid synthesis in soybean fruit. Plant Physiology 120: 1117-1128. 
1050 Wittenbach, Vernon A. 1983. Effect of pod removal on leaf photosynthesis and soluble protein composition of field-grown soybeans. Plant Physiology 73: 121-124.

1052

1053

1054

1055

1056

1057

1058

1059

1060

1061

1062

1063

1064

1065

1066

1067

1068

1069

1070

1071

Wuriyanghan H, Zhang B, Cao W-H, Ma B, Lei G, Liu Y-F, Wei W, Wu H-J, Chen L-J, Chen H-W, Cao Y-R, He S-J, Zhang W-K, Wang X-J, Chen S-Y, Zhang J-S. 2009. The ethylene receptor ETR2 delays floral transition and affects starch accumulation in rice. The Plant Cell 21: 1473-1494.

Yanagisawa S, Yoo S-d, Sheen J. 2003. Differential regulation of EIN3 stability by glucose and ethylene signalling in plants. Nature 425: 521-525.

Yang J, Zhang J, Liu K, Wang Z, Liu L. 2006. Abscisic acid and ethylene interact in wheat grains in response to soil drying during grain filling. New Phytologist 171: 293-303.

Yu B, Gruber M, Khachatourians GG, Hegedus DD, Hannoufa A. 2010. Gene expression profiling of developing Brassica napus seed in relation to changes in major storage compounds. Plant Science 178: 381-389

Zhao F, Bilsborrow PE, Evans EJ, Syers JK. 1993. Sulphur turnover in the developing pods of single and double low varieties of oilseed rape (Brassica napus L). Journal of the Science of Food and Agriculture 62: 111-119.

Zhou L, Jang JC, Jones TL, Sheen J. 1998. Glucose and ethylene signal transduction crosstalk revealed by an Arabidopsis glucose-insensitive mutant. Proceedings of the National Academy of Sciences of the United States of America 95: 10294-10299.

Zhou X, Liu Q, Xie F, Wen C-K. 2007. RTE1 is a Golgi-associated and ETR1-dependent negative regulator of ethylene responses. Plant Physiology 145: 75-86.

Table 1. Expression of genes involved in ethylene and sugar transport/signalling during developmental pod senescence (green to yellow pods) and wound response (0-90min after wounding $)^{1}$.

\begin{tabular}{|c|c|c|c|c|}
\hline Function & Gene & AGI & $\begin{array}{l}\text { Fold change in } \\
\text { senescent pods }\end{array}$ & $\begin{array}{l}\text { Fold change in } \\
\text { wounded pods }\end{array}$ \\
\hline \multirow{4}{*}{ 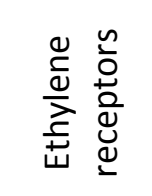 } & ETR1 & At1g66340 & 0.94 & 1.50 \\
\hline & ETR2 & At3g23150 & 2.83 & NP \\
\hline & ERS1 & At2g40940 & 1.70 & 1.99 \\
\hline & ERS2 & At1g04310 & 1.01 & 1.55 \\
\hline
\end{tabular}




\begin{tabular}{|c|c|c|c|c|}
\hline & EIN4 & At3g04580 & 1.93 & 0.86 \\
\hline \multirow{5}{*}{ 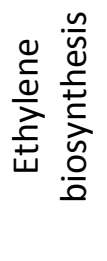 } & ACS2 & At1g01480 & NP & 4.73 \\
\hline & ACS4 & At2g22810 & NP & NP \\
\hline & ACS9 & At3g49700 & NP & NP \\
\hline & ACS11 & At4g08040 & NP & NP \\
\hline & $\mathrm{ACO} 4$ & At1g05010 & 19.80 & 11.39 \\
\hline \multirow{8}{*}{ 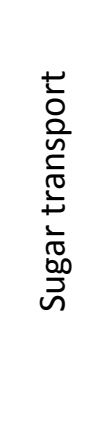 } & GPT1 & At5g54800 & 0.84 & 2.17 \\
\hline & GPT2 & At1g61800 & 0.18 & NP \\
\hline & GLT1 & At5g16150 & 1.12 & 1.11 \\
\hline & SUC2 & At1g22710 & 0.92 & 8.31 \\
\hline & SUC3 & At2g02860 & 1.24 & 1.52 \\
\hline & SUC4 & At1g09960 & 0.77 & 3.54 \\
\hline & SUC5 & At1g71890 & 0.10 & 1.33 \\
\hline & HXK1 & At4g29130 & 0.84 & 2.45 \\
\hline
\end{tabular}

${ }^{1}$ Shaded values indicate a fold increase greater than 1.5; NP indicates no signal present on array. 


\section{Figure legends}

Figure 1. Push-Pull model of resource allocation. Vegetative green organs such as leaves and stems produce assimilates which are pushed into the central pool of resources for that plant. Photosynthetic activity of the pod also contributes to the resource pool early in development, but it becomes a sink during senescence and seed maturation. A negative feedback loop, hypothesised to be mediated by an unknown signal originating from the immature pod, prevents early remobilisation of resources away from photosynthetic organs which is only broken as the pull from the maturing seeds becomes strong enough to initiate remobilisation from the central pool. The strength of the pull is proportional to the number of maturing pods on the plant; hence selective pod removal prevents senescence of the rosette leaves as the number of sinks is reduced.

Figure 2. Ways to manipulate yield. Blue boxes indicate targets strategies for yield manipulation; green boxes indicate the tools that could be used; pink boxes show the consequence of manipulation for each strategy. Coloured edges of blue boxes are linked with lines of the same colour. References in brackets are listed below and in full within the reference section of the main manuscript. (1) Allen \& Morgan, 1972; (2) Taylor et al., 2010; (3) Abreu \& Munné-Bosch, 2009; (4) Wuriyanghan et al., 2009; (5) Yang et al., 2006; (6) Wilen et al., 1990; (7) Maia-Grondard \& Limami, 2010; (8) Gan \& Amasino, 1995; (9) Sorefan et al., 2009. 


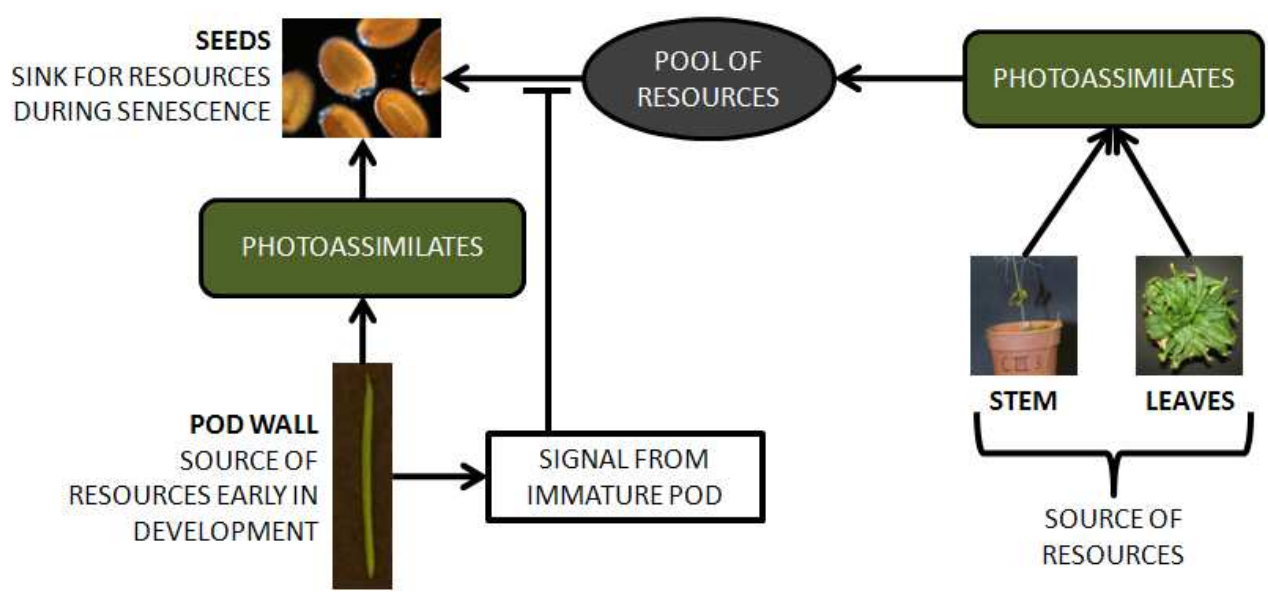

Figure 1. Push-Pull model of resource allocation. Vegetative green organs such as leaves and stems produce assimilates which are pushed into the central pool of resources for that plant.

Photosynthetic activity of the pod also contributes to the resource pool early in development, but it becomes a sink during senescence and seed maturation. A negative feedback loop, hypothesised to be mediated by an unknown signal originating from the immature pod, prevents early remobilisation of resources away from photosynthetic organs which is only broken as the pull from the maturing seeds becomes strong enough to initiate remobilisation from the central pool. The strength of the pull is proportional to the number of maturing pods on the plant; hence selective pod removal prevents senescence of the rosette leaves as the number of sinks is reduced. $34 \times 15 \mathrm{~mm}(600 \times 600 \mathrm{DPI})$ 


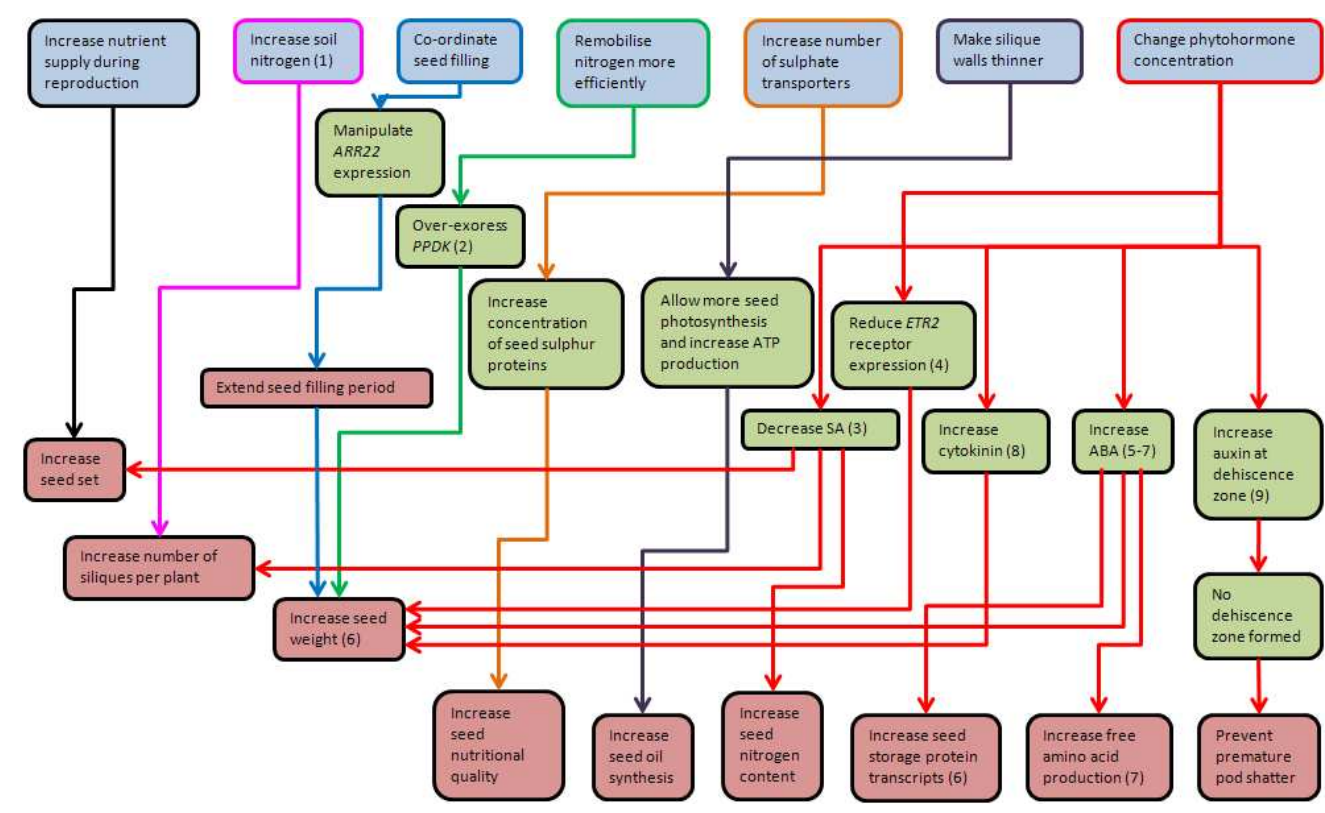

Figure 2. Ways to manipulate yield. Blue boxes indicate targets strategies for yield manipulation; green boxes indicate the tools that could be used; pink boxes show the consequence of manipulation for each strategy. Coloured edges of blue boxes are linked with lines of the same colour. References in brackets are listed below and in full within the reference section of the main manuscript. (1) Allen \& Morgan, 1972; (2) Taylor et al., 2010; (3) Abreu \& Munné-Bosch, 2009; (4) Wuriyanghan et al., 2009; (5) Yang et al., 2006; (6) Wilen et al., 1990; (7) Maia-Grondard \& Limami, 2010; (8) Gan \& Amasino, 1995; (9) Sorefan et al., 2009. $41 \times 25 \mathrm{~mm}(600 \times 600 \mathrm{DPI})$ 